

\section{0q21.2: rs1171614}

O (Carnitine free)
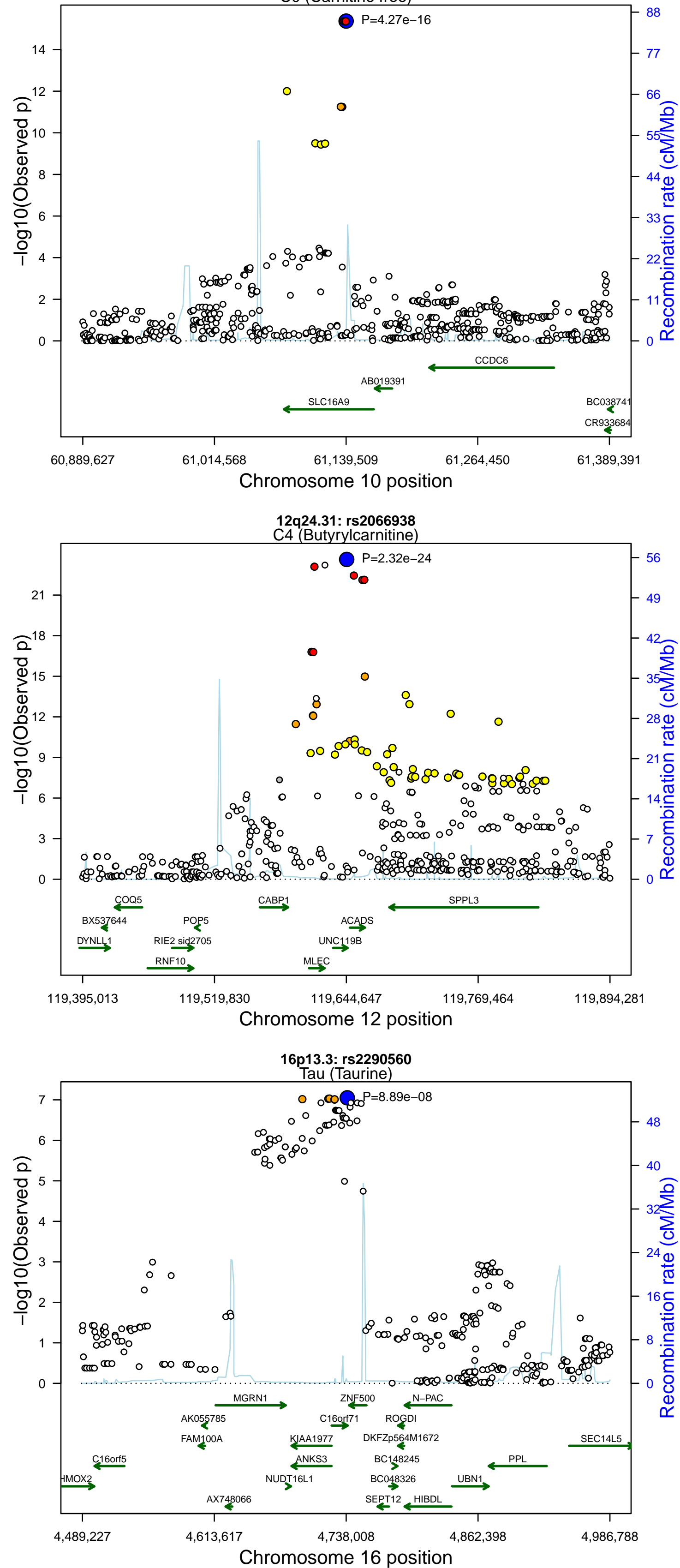

12q23.1: rs11109142

Q1:(Val+Leu|lle)/(Phe+Tyr) ((Valine + Leucinellsoleucine) / (Phenylalanine + Tyrosine) $)$
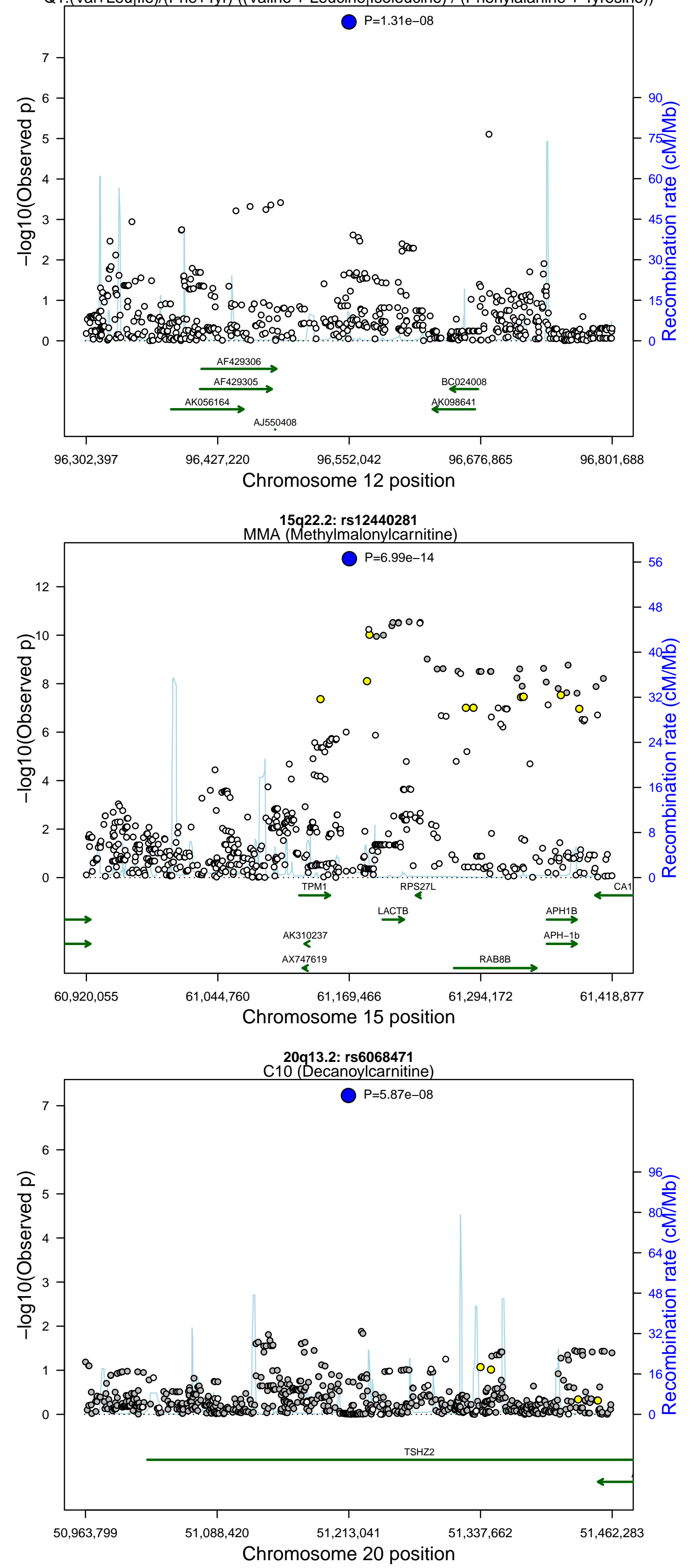
21q22.13: rs1571700

$\mathrm{C} 5 \mathrm{OH}+\mathrm{HMG}$ (2-Hydroxyisovalerylcarnitine)

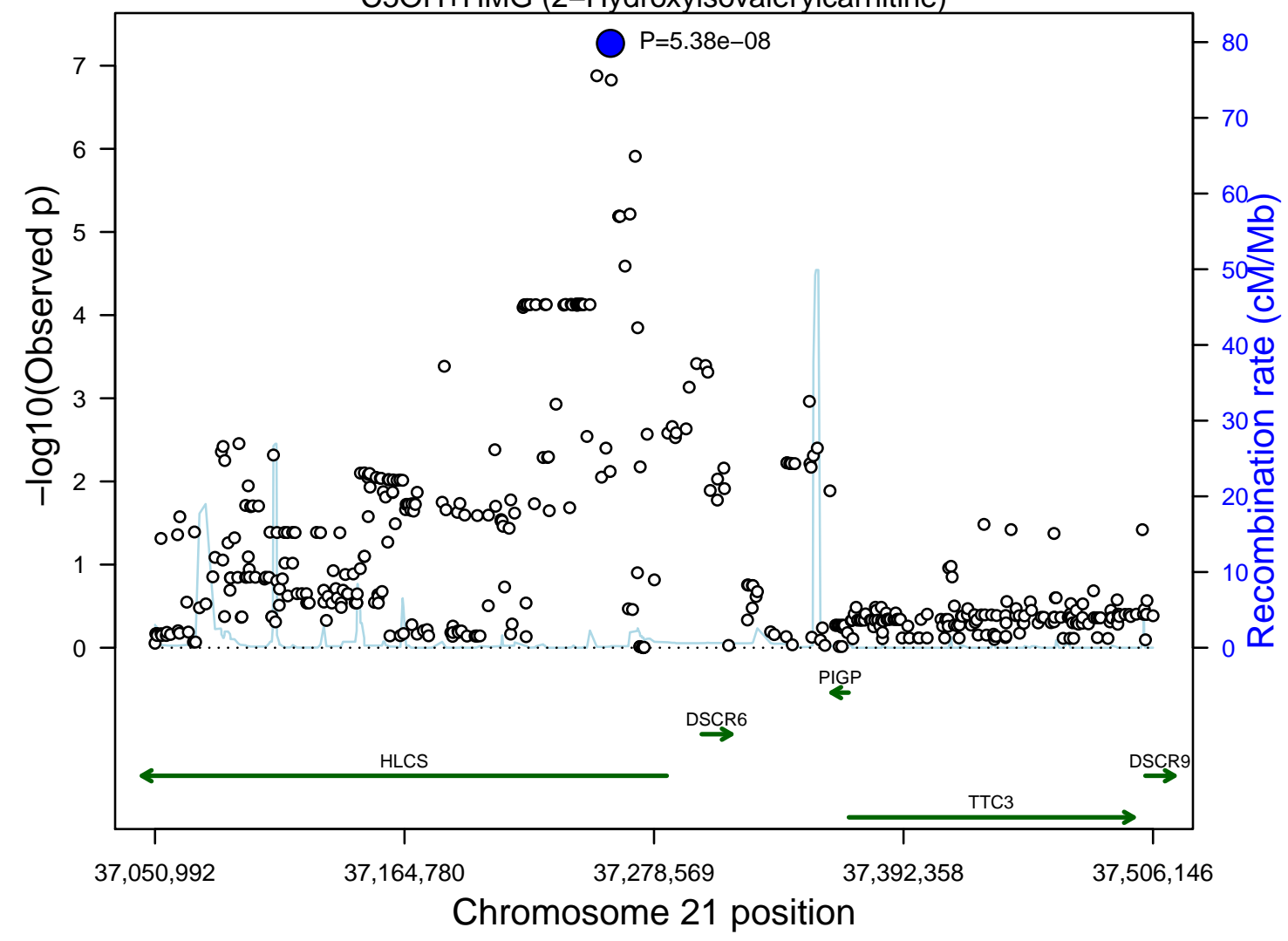

